\title{
DREDGING- A CONSERVATIVE MODALITY TO TREAT KERATOCYSTIC ODONTOGENIC TUMOUR
}

\author{
Ankita Parihar1, Shishir Dubey² \\ 1 Postgraduate Student, Department of Oral and Maxillofacial Surgery, Modern Dental College and Research Centre, Indore, \\ Madhya Pradesh, India. \\ 2Postgraduate Student, Department of Oral and Maxillofacial Surgery, Modern Dental College and Research Centre, Indore, \\ Madhya Pradesh, India.
}

HOW TO CITE THIS ARTICLE: Parihar A, Dubey S. Dredging- a conservative modality to treat keratocystic odontogenic tumour. J. Evolution Med. Dent. Sci. 2018;7(43):4697-4699, DOI: 10.14260/jemds/2018/1048

\section{PRESENTATION OF CASE}

Odontogenic Keratocyst or as now better called as Keratocystic Odontogenic Tumour is a type of cyst with locally aggressive behaviour with high recurrence rate and typical histological appearance and it makes upto $11 \%$ of the total cysts of the jaws.[1] KCOTs can be seen in any part of the jaws, but has higher predilection for the body of the mandible and ascending ramus with peak incidence seen between 1030 years of age and a slight male predominance.[2-4] Radiographically, it can appear as either unilocular or multilocular with well-defined boundaries and scalloped and corticated margins. Its association with impacted tooth has been reported in $25 \%$ - $40 \%$ of cases.[5] Evidence shows its association with displaced, impacted or erupted teeth, displaced roots or extruded teeth.[6] These cases are usually diagnosed during routine dental examination and the frequency of these cases range from $5.5 \%$ to $42.5 \%$.[2,7,8] The parakeratinising variant is more aggressive in terms of growth and shows recurrence post-surgical treatment. They show high level of mitosis in the cystic epithelium with high potential of budding of the basal layer and presence of the daughter cysts in the cystic wall. Usually, they are associated with naevoid basal cell carcinoma syndrome.[9,10] In the year 2005, WHO working group considered the parakeratinising variant of KCOT to be a cystic neoplasm and recommended the term "Kerato-Cystic Odontogenic Tumour."[11] KCOT originates from remnants of the dental lamina and shows following features like sand-like stratified squamous epithelium with a spinous cell layer with a thickness of about 8-10 cells and a corrugated keratinised lining, a thin connective tissue capsule and a lumen which contains variable amounts of desquamated keratin. Parakeratin lining predominates and it is ranging from $83 \%$ to $97 \%$ in a KCOT[12-15] and has invasive properties causing local destruction and extension into adjacent tissues. The reason behind this is its active epithelial proliferation, tumour necrosis factor, prostaglandin-induced bone resorptive properties via interleukins and active collagenases in the fibrous cystic wall.[16-18]

'Financial or Other Competing Interest': None.

Submission 25-09-2018, Peer Review 12-10-2018,

Acceptance 15-10-2018, Published 22-10-2018.

Corresponding Author:

Dr. Shishir Dubey,

132/F, Nehru Nagar,

Opposite MSCB Medical College,

Jabalpur-482003,

Madhya Pradesh,

India.

E-mail: dubeyshishir21@gmail.com

DOI: $10.14260 /$ jemds/2018/1048

(c) $($ i) $(\mathrm{E})$
Multiple surgical approaches were introduced including decompression, marsupialisation, enucleation and resection associated with a number of complications such as loss of bony support of the jaw, deformity, dysfunction and psychological disturbances even after reconstruction. An alternative conservative surgical procedure called the "Dredging Method" can eliminate the tumour, while restoring the normal contour and function of the jaw. The choice of treatment is controversial, but depends on several factors such as patient's age, size of the lesion, location of the lesion and whether the KCOT is primary or recurrent. ${ }^{[19]}$ Complete removal of the KCOT is difficult, because of the presence of thin friable epithelial lining. The presence of satellite cysts and rest of odontogenic epithelium are suggested as reasons for KCOT recurrence. The type of epithelial keratinisation appears to play a key role in the recurrence. Tool for diagnosis and treatment planning was Orthopantomogram (OPG).

The Aim of the Study is to evaluate the Efficiency of Dredging in following Three Cases-

\section{CASE 1}

A twenty eight year old male came to the department giving history of swelling in the lower right jaw region post extraction of 47 around six months back. Clinical examination was performed and a hard, non-tender, diffuse swelling was seen extraorally on right body region of mandible extending to the ramus of the mandible. On intraoral examination, a large swelling extending from 44 to 48 was appreciated. Thereafter, he was sent for a radiographic examination and Orthopantomogram (OPG) was the diagnostic tool of choice. OPG revealed multilocular radiolucency extending from 44 to 48 involving the entire alveolus with only a thin bone remaining intact at the lower border. Incisional biopsy was performed under local anaesthesia, which confirmed the lesion as Keratocystic Odontogenic Tumour.

\section{CASE 2}

A thirty year old female visited our department with a chief complaint of swelling of right lower jaw region, which came to notice three months back. On extraoral examination a hard, non-tender swelling was appreciated over the right lower jaw region. Intraoral examination revealed swelling extending distal to 46. Panoramic examination showed multilocular appearance from body of mandible till ramus of the mandible. Lower border was intact with little expansion of cortex. Incisional biopsy was done and sample was sent to the Oral Pathology Department. Results confirmed the lesion as Keratocystic Odontogenic Tumour. 


\section{CASE 3}

A twenty five year old male came to our department with a history of swelling in the left lower jaw region persisting since last four months. Extraorally, a non-tender and hard swelling was present over the lower left jaw region. Intraorally, the area distal to 36 was swollen upto 38 , even extending till the ramus of the mandible. Radiographic and histopathological examination diagnosed the lesion as Keratocystic Odontogenic Tumour.

\section{DIFFERENTIAL DIAGNOSIS}

1. Histologically: Myxoma, Ameloblastoma, Giant cell granuloma, Odontogenic cysts.

2. Radiographically: Dentigerous cyst (40\%), Residual cysts, Radicular cysts, Lateral periodontal cysts (25\%), Primordial cysts (25\%), Globulomaxillary cyst (10\%), Fibreosseous lesions at initial stages.

\section{CLINICAL DIAGNOSIS}

In all the three cases an extraoral presence of hard, nontender swelling lying over the lower border of the mandible was appreciated. On intraoral examination, a swelling was seen in the posterior part of the mandible reaching upto the ramus of the mandible along with some intraoral discharge. All of these findings were leading the lesion to be diagnosed as Odontogenic Keratocyst.

\section{PATHOLOGICAL DISCUSSION}

Stratified squamous epithelium which is thin and band-like, a spinous cell layer with thickness of about 8 - 10 cells, a corrugated keratinised lining, a thin inflammation-free connective tissue capsule and a lumen containing variable amounts of desquamated keratin is characteristic of KCOT and all the three cases were showing a parakeratin lining.

\section{DISCUSSION OF MANAGEMENT}

Anatomy of the face and oral cavity has direct effects on the functional abilities and aesthetics. Any disease of the oral cavity, which requires surgical intervention becomes inadequate if it causes deformity of face and causes functional inconvenience, aesthetic dissatisfaction and mental agony. So, the treatment of choice should be either conservative or if not then proper steps to rehabilitate the above-mentioned postsurgical problems should be taken. The age of patient, site, nature and extension of the lesion should be considered before choosing the treatment of choice. Dredging is considered to fulfil most of these purposes. After the diagnostic procedures such as $\mathrm{OPG}$ and incisional histopathology confirmed the lesion as Keratocystic Odontogenic Tumour, all of our 3 cases were treated with Dredging under general anaesthesia. Osteotomy was performed to remove perforated buccal cortex for better access to the site and then the whole tumour was scooped, cavity was checked for any remaining daughter cysts. The excavated site was packed using Roller gauze soaked with an ointment or a mix of various ointments. Excised tissue was sent for histopathology. Three days post surgery, roller gauze was removed and the site was irrigated using normal saline and betadine solution and the cavity was packed again with freshly prepared roller gauze soaked in medicated ointments for secondary epithelialisation. Roller gauze snug fitting the cavity prevented any food and debris entrapment, thereby preventing any chance of infection and hampering of the reepithelialisation of the site. All three patients were advised to come for follow-up every three days till one month or immediately if any problem arises. Until now none of the patients have reported to us with features of recurrence as such.

Even after proper enucleation, the daughter cells can be seen in the scar tissue within the bony cavity which leads to its recurrence. Hence, the scar tissue should be dredged out repeatedly to prevent the recurrence as well as to accelerate new bone formation. OPG as well as all of our three cases showed promising results. Dredging led to very low recurrence rates. But often dredging is continued only for restoration of bony defect. For the total restoration, a regular follow-up is essential. The patient should be extremely motivated for long-term duration of follow-ups.

All of our cases were dredged out repeatedly until no tumour cells were found under microscopic examinations. Good healing of the bone was observed in OPG after one year follow-up. New bone formation is accelerated and intrabony pressure is reduced, as scar tissues are removed. Histopathology reports of the scar tissue suggestive of being free of tumours will hence reduce the recurrence.

\section{REFERENCES}

[1] Shear M. Developmental odontogenic cysts. An update. J Oral Pathol Med 1994;23(1):1-11.

[2] Myoung H, Hong SP, Hong SD, et al. Odontogenic keratocyst: review of 256 cases for recurrence and clinicopathologic parameters. Oral Surg Oral Med Oral Pathol Oral Radiol Endod 2001;91(3):328-33.

[3] Maurette PE, Jorge J, de Moraes M. Conservative treatment protocol of odontogenic keratocyst: a preliminary study. J Oral Maxillofac Surg 2006;64(3):379-83.

[4] Zhoa JI, Jiao SL, Chen XH, et al. Treatment of recurrent odontogenic keratocyst with enucleation and cryosurgery: a retrospective study of 10 cases. Shanghai Kou Quiang Yi Xue 2005;14(5):476-8.

[5] Neville BW, Damm DD, Allen CM, et al. Oral and maxillofacial pathology. $2^{\text {nd }}$ edn. Philadelphia: Saunders 2002.

[6] Brannon RB. The odontogenic keratocyst: a clinicopathologic study of 312 cases. Part I. Clinical features. Oral Surg Oral Med Oral Pathol 1976;42(1):54-72.

[7] Chirapathomsakul D, Sastravaha P, Jansisyanont P. A review of odontogenic keratocysts and the behavior of recurrences. Oral Surg Oral Med Oral Pathol Oral Radiol Endod 2006;101(1):5-9.

[8] Morgan TA, Burton CC, Qian F. A retrospective review of treatment of the odontogenic keratocyst. J Oral Maxillofac Surg 2005;63(5):635-9.

[9] Daley TD, Multari J, Darling MR. A case report of a solid keratocystic odontogenic tumor: is it the missing link? Oral Surg Oral Med Oral Pathol Oral Radiol Endod 2007;103(4):512-5.

[10] Habibi A, Saghravanian N, Habibi M, et al. Keratocystic odontogenic tumor: a 10-year retrospective study of 83 cases in an Iranian population. J Oral Sci 2007;49(3):229-35. 
[11] Philipsen HP. Keratocystic odontogenic tumor. In: Barnes L, Eveson JW, Reichart P, et al, eds. WHO classification of tumors. Pathology and genetics of head and neck tumors. Lyon: IARC Press 2005:306-7.

[12] Kakarantza-Angelopoulou E, Nicolatou O. Odontogenic keratocysts: clinicopathologic study of 87 cases. J Oral Maxillofac Surg1990;48(6):593-9.

[13] Crowley TE, Kaugars GE, Gunsolley JC. Odontogenic keratocysts: a clinical and histologic comparison of the parakeratin and orthokeratin variants. J Oral Maxillofac Surg 1992;50(1):22-6.

[14] Browne RM. Per[cyst]ent growth: the odontogenic keratocyst 40 years on. Ann $R$ Coll Surg Engl 1996;78(5):426-33.

[15] Brannon RB. The odontogenic keratocyst. A clinicopathologic study of 312 cases. II. Histologic features. Oral Surg Oral Med Oral Pathol 1977;43(2):233-55.
[16] Vered M, Buchner A, Dayan D, et al. Solid variant of odontogenic keratocyst. J Oral Pathol Med 2004;33(2):125-8.

[17] Giuliani M, Grossi GB, Lajolo C, et al. Conservative management of a large odontogenic keratocyst: report of a case and review of the literature. J Oral Maxillofac Surg 2006;64(2):308-16.

[18] Kolokythas A, Fernandes RP, Pazoki A, et al. Odontogenic keratocyst: to decompress or not to decompress? A comparative study of decompression and enucleation versus resection/peripheral ostectomy. J Oral Maxillofac Surg 2007;65(4):640-4.

[19] Farish SE, Di Leo CT. A case report. Under diagnosis of an odontogenic keratocyst: common cyst can be controversial lesion. Journal of the American Dental Association 1994;125(6):738-41. 